\title{
Review
}

\section{Social networks and popular understanding of science and health: sharing disparities}

\section{Ann Grand}

Brian G. Southwell (2013), Social networks and popular understanding of science and health: sharing disparities, Johns Hopkins University Press, Baltimore and RTI Press, Research Triangle, 106 pp, ISBN 13 978-1-4214-1324-2

\begin{abstract}
In this book, Brian G. Southwell discusses how disparities in information-sharing arise and what can be done to alleviate them. In all sorts of ways and for all sorts of reasons, people have always sought to share information among their family and other social networks. However, this sharing has never been equal: inevitably, some people are better-informed than others and some are more socially-connected than others. At first glance, the plethora of communication tools and technologies available nowadays should help democratise information and reduce disparity but differences in how, when and with whom information is shared create conversation gaps and maintain inequalities. Southwell explores and catalogues information-sharing behaviours, discusses the factors that affect how and why we share information and addresses the questions of why disparities in information-sharing matter and what we can do about the gaps between 'information-haves' and 'information have-nots'.
\end{abstract}

For as long as humans have had speech, people have sought to share information with each other. And as long as that sharing has been going on, some people will always have been better-informed than others and some people more well-connected than others. Many people believe that modern communication technology, digital social networking and other tools can democratise information and help overcome knowledge disparities. However, Brian Southwell's view is that a more networked future won't necessarily guarantee an equal society. Using a wide variety of case studies from the passing of the Affordable Care Act (2012) in the U.S.A., the announcement of the discovery of the Higgs-boson particle, to the after-effects of Hurricanes Katrina and Sandy, he begins by examining the ways that information spreads among people, from newspapers, radio and television to online sources and digital social networks. But Southwell's real interest is in disparities in how information is shared; or rather, how sometimes it is shared and sometimes it isn't.

It will come as no surprise to readers of this journal that there are severe gaps in knowledge between the 'information haves' and the 'information have-nots'. Southwell sug- 
gests that beyond information gaps lie 'conversation gaps'; some groups are simply more likely to talk about this topic or that than others, with consequences for how information spreads through society. Not only that but 'to he that hath, to him shall be given': that is, those already rich in information are likely to become even richer, exacerbating gaps. If the information you aren't sharing is merely who you think should win the Great British Bake-off or the City-Rovers weekend derby, the social consequences are slight. However, if the information not being shared is concerned with science or health, the ramifications could be tragic.

Southwell first offers a catalogue of information-sharing behaviours, from the ancient and low-tech art of conversation to behaviours facilitated by digital technologies. But what matters just as much as how we share information is whether we share it; people vary in their tendency to engage with each other, whatever the route they choose. If information-sharing behaviours vary because of social disadvantage, again, the consequences can be considerable. Southwell suggests three factors underpin why information about science and health is not universally discussed: individual-level factors (who we are - our socio-economic circumstances, our level of education and understanding and how much we think the topic is relevant to us), community-level factors (the extent to which our community is equipped to facilitate discussion, from Internet availability to the quality and abundance of local coffee shops and the existence or otherwise of community leaders or people in a position to exert influence) and finally content-level factors (what aspects of a topic are likely to spark or close down discussion and sharing).

Of course, as Southwell points out, uneven access to information is not a single event: information isn't simply shared once then left alone; information can be reinforced, so that a person's engagement with a topic can be nourished and grow, it can be neglected and so the attention paid to a topic withers or we can develop resistance to continued argument. Variations in our social networks lead to different degrees of information salience and review, as well as to differences in information uptake and sharing.

Finally, Southwell addresses the question of why disparities in information-sharing matter and what we can do to address them. Perhaps, he suggests, we can do nothing; disparities are inevitable. This is an argument that will strike a chord with many in science communication, for it has been used as an argument against efforts to engage with communities beyond professional scientists and enthusiastic amateurs. However, with his focus on the distribution of health-related information, this is not an argument that can be sustained: people need the information that will enable them to make sensible decisions about their and their families' health, therefore he suggests a series of potential interventions. First, boost the collective confidence; individually, we are unlikely to pass on information we don't fully understand and as a community, we can then rely on the collective memory of our group. Second, meet people where they are; ideas are most likely to spread among networks when they resonate with people's lives and concerns. Third, build the infrastructure of community connection, or strengthen the connections that already exist, whether the networks are local, national or international. Increasing the number of voices that are contributing to debate will enrich and enhance our communi- 
ties, Southwell closes by writing, but we must begin by acknowledging the reality of the information disparities that exist within and between communities.

Southwell writes well; the language is clear and the arguments flow readily. I would recommend this slim paperback as an introduction to the topics of information-sharing, the role of social networks and the effects of information disparity. However, for people already familiar with the tenets of public engagement and science communication, there is nothing especially novel to be found in this book.

\section{Author}

Ann Grand is a part-time Research Associate with the Open University Catalyst for Public Engagement with Research. Her work in this project focusses on researchers' practice in digital engagement and how public engagement with research can be supported and facilitated through digital technologies.

She is also a part-time Research Fellow in the Science Communication Unit, University of the West of England, Bristol. She works with academic and research staff in the Faculty of Health and Life Sciences to develop collaborative projects, specifically focussing on innovative strategies to embed public engagement within research projects.

Ann has over ten years' experience in informal, face to face science communication as the volunteer web host for the national and international café scientifique (science café) network. Through the website, she supports and mentors new and existing volunteer café organisers around the world. E-mail: Ann2.Grand@uwe.ac.uk.

How TO CITE: A. Grand, "Social networks and popular understanding of science and health: sharing disparities", JCOM 13(04)(2014)R01. 